\title{
Spatial clustering of emergency department visits by asthmatic children in an urban area: south-western Detroit, Michigan
}

\section{Jaymie R Meliker', Jerome O Nriagu', Adnan S Hammad², Kathryn L Savoie ${ }^{2}$, Hikmet Jamil ${ }^{3}$ and Jeffrey M Devries ${ }^{4}$}

'University of Michigan, School of Public Health, Department of Environmental Health Sciences, Ann Arbor, Michigan, ${ }^{2}$ Arab Community Center for Economic and Social Services (ACCESS), Dearborn, Michigan, ${ }^{3}$ Wayne State University, Detroit, Michigan and ${ }^{4}$ Oakwood Healthcare System, Dearborn, Michigan, USA

ABSTRACT

Objective

Design

Sample

Results

Implications for practice
This ecological study evaluates the correlation of asthma clusters with outdoor air pollution, race, and household income in South-western Detroit, Michigan.

To attain this objective (1) a geographic information aystem (GIS) is utilized to evaluate the relationships between rates of emergency department (ED) admissions for asthma, race, and socio-economic status at the neighborhood block group level of analysis; (2) cluster statistical analyses are performed using Geomed software; and (3) the asthma risk from industrial air pollution was evaluated with windrose data and Screen3 air pollution model.

Data from five major hospitals with ED admissions of asthma patients (code 493), aged $0-15$ years, are used to select a region of analysis with good geographical representation based on the catchment areas of hospitals in the study. A total of 2067 of the reported cases between 1 January 1993 and 30 June 1998, are successfully geocoded to a map, generating a no-match rate of $8.4 \%$. Data on racial characteristics, population density, and household income levels are obtained from neighborhood block groups in the 1990 census report. Locations of major polluting industries within the study area are obtained from the Toxics Release Inventory.

Spatial analysis identified a local asthma cluster roughly $2 \mathrm{~km}$ east (the predominant downwind direction) of the second and third largest air polluters (in terms of tonnage) in Wayne County. Evaluation of the industrial pollution with a focused cluster test, Screen3 air pollution model, and windrose figures, displayed weak association between ED asthma admissions and estimated levels of outdoor air pollution from these two facilities. The neighborhood block groups in the local asthma cluster are more closely correlated with high proportions of African Americans and low median household income.

This study illustrates the strengths and weaknesses of GIS in the public health arena. It highlights the difficulty of disentangling the effects of exposure to outdoor air pollutants and socio-economic factors on ED 
asthmatics (reflecting asthma severity) among an urban population. This study also illustrates the need for population-based, as opposed to hospitalbased, asthma data, and the need for block-groups, as opposed to zip codes, as a spatial unit of analysis in the evaluation and analysis of asthmarelated risk factors.

Keywords air pollution, asthma, environmental epidemiology, GIS, spatial analysis

\section{Introduction}

Asthma was a growing medical concern at the end of the twentieth century and continues to be of major concern as we embark on the twenty-first century. A 15-year study of asthma prevalence from 1980 to 1994 in the US National Health Interview Survey (NHIS) showed a $75 \%$ increase in asthma prevalence for all ages. ${ }^{1}$ This increase appears to be growing at a faster rate for children, with the most notable increase of $160 \%$ occurring in the 0-4 years age group. ${ }^{2}$ Between 1993 and 1994, there were 27 million visits to the doctor's office or hospital in which the principal diagnosis was asthma, an average of 13.7 million visits per year. During that period, there were, on average, 11 million visits to office-based physicians, 1.6 million visits to hospital emergency departments (ED), and 1 million visits to hospital outpatient departments. ${ }^{2}$ Those 1.6 million ED visits account for roughly $1.6 \%$ of all ED visits in the US. ${ }^{3}$ Asthma accounts for 2.2 million pediatrician visits and 10 million missed school days per year. ${ }^{4}$ On average, 10.8 children out of every 1000 children will visit the ED due to asthma, annually. ${ }^{2}$ In 1996, asthma was the second leading cause of childhood ED visits, behind accidents, in the United States. ${ }^{5}$

Although there is a genetic component to asthma, many believe that the increase in asthma prevalence over the past three decades is much too great to be solely attributed to genetic variations. ${ }^{6}$ Environmental factors such as outdoor air pollution have been suspected to be implicated in the increasing prevalence of asthma, although there have been conflicting results. A study in East and West Germany found higher asthma levels in the lesser-polluted West Germany and attributed those higher rates to lifestyle factors and decreased ventilation in the housing in West Germany. ${ }^{7,8}$ Furthermore, there has been a general trend toward decreases in ambient levels of almost all air pollutants except for nitrous oxides, yet there has been an increasing trend of asthma. Some of the most compelling evidence in support of an association between outdoor air pollution and asthma is found in two studies performed by Pope in the Utah, Cache, and Salt Lake Valleys of Utah. ${ }^{9,10}$ In these studies, a steel mill in the Utah Valley, the primary source of $\mathrm{PM}_{10}$, was closed and then reopened, thereby creating a natural period of decreased exposure. Pope found that children's hospital admissions for asthma and bronchitis were approximately two times higher during the winters when the steel mill was operating, compared with the winters when it was closed; this trend in childhood hospitalization was not seen in neighboring valleys. Several large observational studies have used timeseries analysis to identify a small but significant correlation between asthma and particulate matter, nitrogen oxides, sulphur oxides, and ozone..$^{11,12}$ Several laboratory studies have demonstrated a significant correlation between air pollutants and lung function; however, few laboratory studies have demonstrated a clear association with asthma. ${ }^{13,14}$

ED admissions by asthmatics are of particular concern in urban, low-income, African American populations. ${ }^{15,16}$ In 1993 and 1994, 19.6 out of every 1000 African Americans visited the ED on an annual basis to treat an asthma episode. This rate is about 
four times higher than those for whites or other minority populations. ${ }^{3}$ Even though many studies have been performed in urban areas, the causes of the differential risks as they pertain to race and socio-economic status (SES) are not well understood. ${ }^{15-18}$ It is generally recognized that higher rates of ED admissions for asthma are due to multiple factors such as air pollution, lack of access to medical care, genetic predisposition, and a general lack of both financial resources and a social support network to effectively manage the disease on a long-term basis. ${ }^{17,18}$

Most work involving a geographic information system (GIS) and health has involved the generation of maps with haphazard assignment of color ranges which can lead a reader to conclude that clusters exist, when they actually do not exist, and vice versa. The preponderance of spatial visualization maps unaccompanied by spatial analytic techniques is attributable to both (1) the unavailability of tools for spatial analysis of GIS maps and (2) a lack of knowledge about spatial statistics by many health professionals. ${ }^{19}$ There have been several strong studies that investigated whether the perceived spatial pattern of health data is statistically significant ${ }^{20-22}$ but in general, the integration of GIS, spatial analysis, and public health data is still in its infancy. In order to use GIS to advance knowledge in environmental epidemiology, a systematic approach should be instituted. ${ }^{19} \mathrm{~A}$ hypothesis should be formulated before looking at the data or the data should be used to generate a hypothesis. However, the same data cannot be used to evaluate the hypothesis, as to do so would create pre-selection bias in favor of confirming the perceived pattern. ${ }^{19}$ In this study, industrial air pollution, racial status, and low SES were hypothesized to be risk factors for asthma before the data were collected. Once the data are collected and a map is generated, spatial analyses should be performed to evaluate if spatial patterns actually exist, to support the hypothesis.

There have been very few studies involving the spatial association between risk factors and rates of asthma. ${ }^{23,24}$ Claudio et al. ${ }^{23}$ compared the risk factors of race and SES at the zip code level of analysis and found large correlations between high asthma hospitalization rates and zip codes of low SES and/or percentage of minorities in the population. Dunn et al..$^{24}$ evaluated the proximity of a factory to home addresses of asthmatics and found an increased prevalence of asthma in a region downwind from the factory. Both of these analyses made use of a GIS. The present study goes several steps further than the previous work by (1) evaluating rates of ED admissions for asthma, race, and SES at the neighborhood block group level of analysis, a significantly smaller unit than the zip code; (2) utilizing Geomed software (Biomedware, Ann Arbor, MI, USA) to perform both local and focused cluster statistical analyses; and (3) incorporating windrose data and Screen3 air pollution model to evaluate the risk of the industrial pollution as it pertains to ED asthma admissions.

\section{Data and methodology}

\section{Health data}

Daily ED visits for asthma were obtained from five hospitals and one ambulatory file in the western suburbs of Detroit for the period of 1 January 1993 to 30 June 1998. The following categories of information were included for each patient: race, gender, age, date admitted, date released, disease code, street address, town, and zip code. Only children aged 0-15 and asthma patients (International Classification of Disease code 493) were included in the study. No letter of informed consent was needed from the patients, just a confidentiality agreement with the hospitals. None of the patients are listed at the home address, but rather are mapped based on their neighborhood block group, to ensure patient confidentiality and privacy, as per the agreement with the hospitals.

There were 7320 different ED visits for asthma over the five-and-a-half year time period with 4584 of the 7320 being different patients and 2736 of the ED visits were repeat visits. Those 2736 repeat visits were made by 1397 different individuals. To avoid doublecounting in the spatial analysis, the 2736 repeat visits were removed from the study. This spatial analysis must avoid double-counting to ensure that areas with high rates of ED admissions for asthma are not disproportionately biased by one or two extremely severe asthmatics who visit the ED multiple times during the period of this study. In the remaining 4584 cases, 150 were missing gender information and 1200 were missing race information. Due to racial misclassification and the need to protect the privacy of the patients, census block group data are used for all analyses which involve a racial component. 


\section{Geographic information system data analysis}

Several different base maps were utilized to represent the Wayne County region in Arcview 3.1 (ESRI, Redlands, CA, USA): zip codes, neighborhood block groups, and streets. The Wayne County neighborhood block group data were a Wessex file and the Wayne County street data and Michigan zip code data were ESRI Tiger files. The demographic data attached to the neighborhood block groups were generated from the 1990 census report. There is a possibility that population shifts occurred between the time of the census (1990) and the period of the study (1993-98). Unfortunately, the population changes cannot be adequately determined until the 2000 census is published. The home addresses of the 4584 cases were geocoded to the street file. The 4197 asthma patients successfully geocoded to the map, yield an $8.4 \%$ nomatch rate. This $8.4 \%$ error is due to incorrect data entry of the address when the patient was admitted at the hospital and/or errors in the street file such as missing streets. The 4197 correctly matched patients were then counted in each block group to protect the privacy of the asthma patients.

A script called 'ptinpoly' (http://www.personal.umich. edu/ schlossb/gis/free.htm) was imported into Arcview 3.1 to count the number of points (asthma patients) in each polygon (neighborhood block groups). The block groups were then coded with either patterns or colors to show the rate of ED admissions in each block group (asthma patients/children aged $0-15$ years). Any block group with less than 30 children was not included in the figures or in the linear regression model as a means of controlling for outliers. (As an example, one block group had a 0.66 rate of ED admissions but it only had nine children according to the 1990 census data). A script within Arcview 3.1 was utilized to locate the latitude-longitude coordinates of the centroid of each block group. These centroid coordinates are necessary for some spatial analyses.

Locations and rankings of major industrial polluters in Wayne County were obtained from both the Toxics Release Inventory (http://www.epa.gov/tril) and the Environmental Defense Fund's (EDF) Scorecard webpage. (http://www.scorecard.org) Geocoding was again performed to map the locations of the industrial facilities located within the region of analysis. The second and third largest polluters (in total tons of air releases) in Wayne County are located in this region. Together, these facilities produce $838393 \mathrm{~kg}$ of air pollutants per year. One other facility in the region produces $117411 \mathrm{~kg}$ of air pollutants per year. Other than that one facility, no other facility in the region produces more than $25000 \mathrm{~kg}$ of air pollutants per year. Furthermore, if the facilities are ranked on EDF's Scorecard by total release of suspected respiratory toxicants, these two facilities rank first and third in the county. The two facilities primarily produce volatile organic compounds, as indicated by Table 1. None of these chemicals have been shown to be associated with occupational asthma ${ }^{25}$ although they are suspected respiratory air toxicants according to the USEPA Health Effects Handbook for Hazardous Air Pollutants and the National Institute for Occupational Safety and Health's Registry of Toxic Effects of Chemical Substances. ${ }^{26,27}$ The two facilities are both involved in the coating and assembly of automobiles.

\section{Region selection}

Figure 1 shows the location of the hospitals in the region. The polygon shows the appropriate region of analysis that is well represented by the data. Every patient in this polygon is either within a $7-\mathrm{km}$ radius of one of the hospitals in this study or is closer to one of the hospitals in the study than one of the competing hospitals. There are some asthma patients outside of this polygon who attended a hospital in this study, but there is a high probability that the competing hospitals would also have considerable numbers of asthma patients outside of this polygon. Inside this polygon, the region of analysis, we believe that there are few asthma patients who would attend one of the competing hospitals. This is because the other hospitals do not offer special ED services for asthmatics or low-income individuals, according to the Wayne County Department of Emergency Services (Miljan B, 1999, personal communication). This polygon contains 411 block groups, a major portion of 15 different zip codes, and 2067 childhood asthma patients. So the initial patient population of 4584 is now reduced to 2067 childhood asthma patients who comprise all of the asthma cases that are evaluated in this study. 
Table 1: Air releases of chemicals by automobile factories

\begin{tabular}{lrrrr}
\hline & $\begin{array}{c}\text { Factory } 1 \\
\text { Air releases } \\
\text { (kg/ year) }\end{array}$ & $\begin{array}{c}\text { Factory } 2 \\
\text { Air releases } \\
(\mathrm{kg} / \text { year) }\end{array}$ & $\begin{array}{c}\text { Suspected respiratory } \\
\text { toxicants }\end{array}$ & $\begin{array}{c}\text { Total of both factories } \\
\text { Air releases } \\
\text { (kg/ year) }\end{array}$ \\
\hline 1,2,4-Trimethylbenzene & 4129 & 20192 & Yes & 24321 \\
Benzene & 24 & 31 & Yes & 54 \\
Certain glycol ethers & 5915 & 5027 & Yes & 10942 \\
Copper compounds & 112 & 2 & Yes & 114 \\
Cumene & 635 & 628 & No & 1263 \\
Cyclohexane & 1 & 1 & No & 2 \\
Ethylbenzene & 8170 & 23786 & Yes & 31955 \\
Ethylene glycol & & 2679 & Yes & 2679 \\
Methanol & 3393 & 9179 & Yes & 12571 \\
Methyl ethyl ketone & 10536 & 11161 & Yes & 21696 \\
Methyl isobutyl ketone & 19964 & 32754 & Yes & 52719 \\
Methyl tert-butyl ether & 237 & 299 & Yes & 536 \\
$N$-butyl alcohol & 9549 & 33201 & Yes & 42750 \\
$N$-hexane & 15 & 19 & Yes & 34 \\
Toluene & 3482 & 6946 & Yes & 10429 \\
Xylene (mixed isomers) & 72634 & 89732 & 340790 & 162366 \\
Zinc compounds & 112 & 2 & 235639 & 114 \\
All chemicals & 138907 & & & 374546
\end{tabular}

This information includes both stack and fugitive/non-point emissions. However, the vast majority of the emissions come from the stack. The source of this information is EPA's Envirofacts Warehouse for 1998. The units are kilograms per year. Information about suspected respiratory toxicants is from USEPA Health Effects Notebook for Hazardous Air Pollutants and National Institute for Occupational Safety and Health's Registry of Toxic Effects of Chemical Substances.

\section{Spatial analysis}

A Global Moran Coefficient (MC) is calculated with the Mapstat script (http://sun2539.sph.umich.edu:2000/ geomed/modules/digitize/lab.html) for rates of ED admissions, median household income per block group, and African Americans per block group. The MC is a measure of autocorrelation within a particular variable. In other words, are rates of ED admissions for asthma in one area more likely to be similar in an adjacent area than in an area that is farther away? Allowing $N$ to represent the number of block groups, $w_{i j}$ to be a weight which represents the geographical proximity between block groups $i$ and $j, S_{0}$ to represent the sum of the weights, and $z$ to represent the rate of ED admissions in a block group, the $M C$ is based on the equation: $\mathrm{MC}=\left(N \times \Sigma \Sigma\left(w_{i j} \times z_{i} \times z_{j}\right)\right) /\left(S_{0} \times \Sigma z_{i}^{2}\right)$. A MC value greater than zero indicates positive spatial autocorrelation. Positive spatial autocorrelation generally suggests that nearby areas have similar disease rates, thereby indicating spatial clustering. ${ }^{28}$ Geomed software's Local Moran Test is utilized to identify local clusters for (1) rates of ED admissions for asthma; (2) median household income per block group; and (3) proportion of African Americans per block group. The Local Moran Test is a localized version of the global MC and it detects spatial autocorrelation around a particular block group; the output can be interpreted as an indicator of local spatial clusters. ${ }^{29}$ The null hypothesis is that there is no association between the value observed at a specific location and the values observed at nearby sites. The output is based on 9999 Monte Carlo runs of this data distribution, and uses an alpha value of 0.008 with the Bonferroni adjustment. A $p$-value smaller than 0.008 is indicative of a region of block groups whose values significantly differ from the values expected under the null hypothesis. Geomed's Lawson and Waller's Score Test is also utilized to evaluate whether there is clustering that is focused around the two factories in this study. ${ }^{30}$ The null hypothesis is that the block groups surrounding the factories have a common disease rate. Allowing $g$ to represent exposure and decrease as a block group gets farther from the point source, and allowing $O$ and $E$ to represent the observed and 


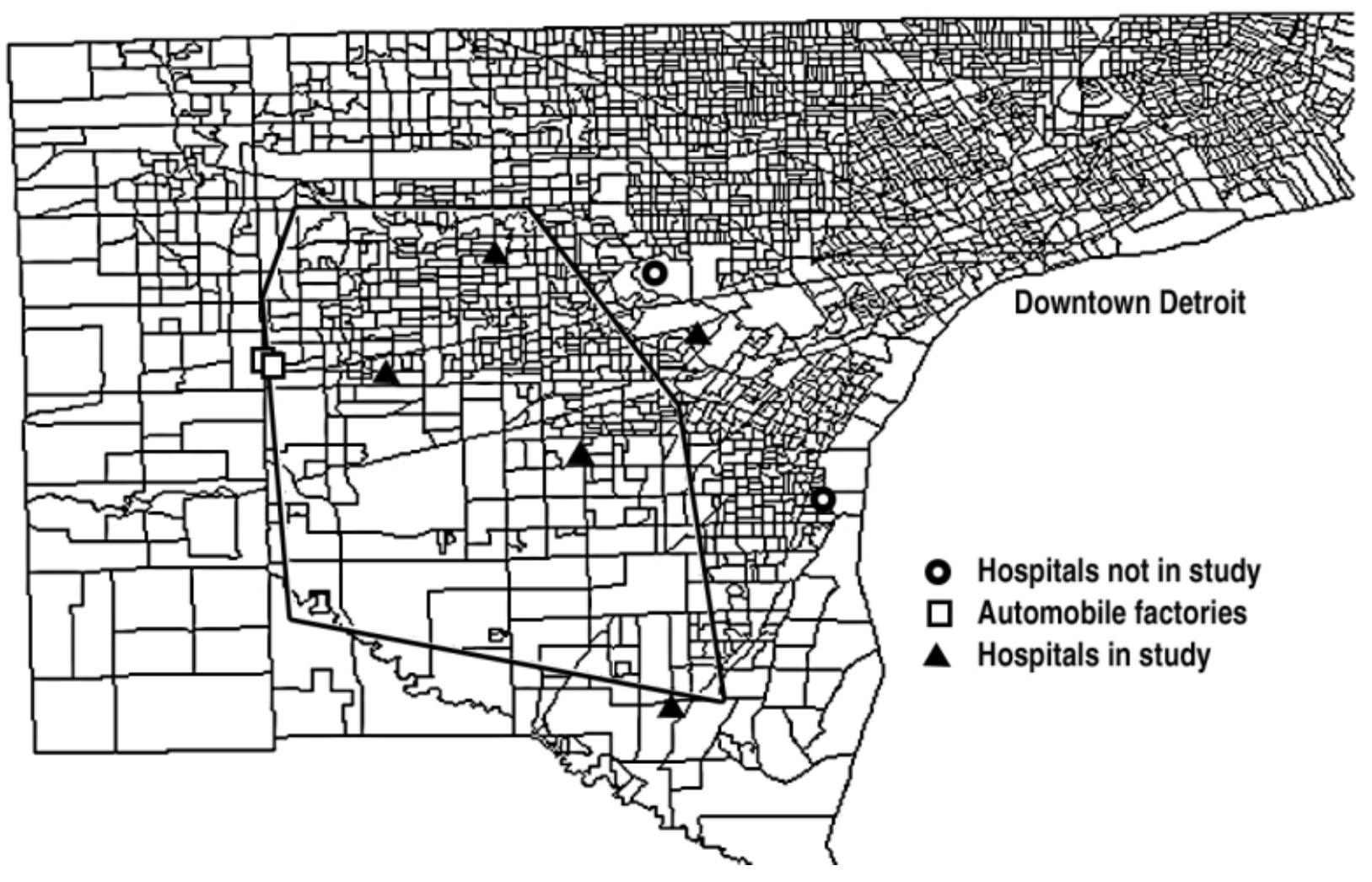

Figure 1: Region well-defined by hospital data. The polygon represents the region which is presumed to be well-represented by the hospital data from the five hospitals in the study (triangles). The hospitals not in this study (circles) are assumed to not get their asthma patients from within this polygon. The two overlapping squares represent the locations of the second and third largest air polluters, in tonnage, in Wayne County.

expected rates in the block group, respectively, the Lawson and Waller's Score Test is based on the equation $U=\Sigma g \times(O-E)$. The score test detects a decreasing trend in disease incidence associated with declining exposure to a point-focus. The score test also uses a Monte Carlo simulation of 9999 runs to generate its frequency distribution. A $p$-value of 0.05 is considered an extreme value and is indicative of clustering around the point-focus.

\section{Outdoor air pollution analysis}

EPA approved Screen3 outdoor air pollution model (http://www.epa.gov/ttn/scram) is a Gaussian dispersion model, primarily used to determine the region which is most heavily impacted by outdoor air pollution from a given source. As its name would indicate, Screen3 is primarily a screening model, designed to predict pollutant concentration for given meteorological and industrial source parameters. In this study, Screen3 is utilized to determine (1) if the worst case outdoor air pollution generated from these two facilities could ever be located in the region of the asthma cluster and (2) if the outdoor air pollution would blow toward the asthma cluster, given the wind direction on that day. The two facilities were treated as one source in the model. Specific information about the pollution history of these two facilities is obtained from EPA's Envirofacts Database (http://www.epa.gov/enviro/ index_java.html) EPA's Toxic Release Inventory and EDF's Scorecard. The following input parameters are assumed in running the model: ambient air of $293 \mathrm{~K}$, no receptor height above the ground, urban setting, no building downwash, and no complex terrain. The emission rate is $131 \mathrm{~g} / \mathrm{sec}$, calculated using a worstcase scenario by taking the worst year of emissions over the study period (1994: $2.35 \times 10 \mathrm{E} 9 \mathrm{~g}$ ) and dividing these emissions by the smallest number of operating seconds per year $(1.79 \times 10 \mathrm{E} 7 \mathrm{sec})$. The other inputs are unknown and are given ranges of values which are assumed to be reasonable for the automobile finishing facilities, according to EPA's Envirofacts Database: stack height of $25-60 \mathrm{~m}$, inside diameter of 
stack of $0-1 \mathrm{~m}$, exit velocity of $9-15 \mathrm{~m} / \mathrm{sec}$, and exit temperature of $300-600 \mathrm{~K}$. The closest meteorological information about air stability and atmospheric ceiling height is 60 miles away so the air stability classes are given the full range of possibilities of A-F. Weather data were gathered from the Wayne County Air Quality Laboratory (WCAQL) and the National Climatic Data Center (NCDC). Wind direction data were measured once per hour by the WCAQL and were available for intermittent periods of 1993-98, recorded from a monitoring station about $15 \mathrm{~km}$ East of the facilities. Wind speed data were available in daily values from the NCDC, and were measured at Detroit Metro Airport, about $5 \mathrm{~km}$ south-east of the facilities. The Screen3 Model was run for 18, 19 and 20 September and 13 and 14 November, 1993, 1995, and 1996. The model could not be run for all 5 years because some weather data were missing in the other 2 years. These dates were selected because they occur in the autumn, when there are, in general, an increased number of asthma attacks. The model was also utilized over the period 15-30 September 1997, one of the three highest 16-day periods of asthmatic ED visits.

EPA approved WRPlot ${ }^{25}$ is a windrose plotting program. The only weather data found on the website, which are capable of being read by WRPlot, is from 1984 to 1992 and are measured at Detroit Metro Airport, which is located within the region of analysis. Using 1990-92 data, windroses are plotted for both yearly data and just for the month of September. All three years show similar results, so it may be reasonable to assume that the yearly and monthly plots from 1990 to 1992 would be representative of the wind patterns in 1993-98. As these wind data are not entered into the Screen3 model, this assumption will have minor impacts if it is incorrect. The windroses are primarily incorporated as a visual aid of the wind speed and direction in this region.

\section{Spatial association analysis}

A stepwise multiple linear regression procedure is performed in SAS (SAS Institute, Inc., Cary, NC, USA) to evaluate the role of median household income and proportion of different races in block groups as possible predictor variables for rates of ED admissions. The model includes the possibility for interaction terms between the different surrogates for race and class. Residual tests and tests of normality are performed and indicate that the model is not violating any assumptions. However, there is autocorrelation within the data set which may be viewed as the presence of redundant, non-independent information in the data. To account for this redundancy, the sample size $N$ is adjusted to relate spatially autocorrelated data to equivalent hypothetical independent and identically distributed data. The 411 block groups are reduced to 218 block groups with the aid of a simplification equation. $^{31,32}$ In brief, by taking the square root of the Moran's coefficient for the predictor $(p x)$ and the square root of the $M C$ for the response variable (py), one can calculate the effective sample size $\left(N^{*}\right) .{ }^{33}$ The equation derived is defined as follows: $N^{*}=1+$ $(N-3)^{*}(1-p x \times p y) /[1+(p x \times p y) / 6]$.

\section{Results}

As not all of the patients have race and gender information, the following information is not used for analyses, but just for descriptive purposes. Those patients with gender and race information show a ratio of 1.6 boys to every one girl and two white children to every one African American child. This proportion of African Americans (0.33) is very high considering that the background population in the region has a proportion of just 0.09 , thereby indicating that African Americans disproportionately use the ED to treat asthma. These gender and race ratios for children are similar to those found in the literature., ${ }^{1,2}$ There is a marked seasonality in the ED data, with a large peak of hospital admissions in September, October, and November and a smaller peak in March and April. The large peak in autumn is in agreement with other studies which demonstrate increased hospitalization due to an asthma episode in the Autumn months ${ }^{9,34}$ One possible explanation for this autumn trend is the renewed use of an allergen-storing ventilation system which was inoperable all summer at the beginning of the cold weather season. ${ }^{35}$

Figure 2 shows the spatial distribution of the rates of ED admissions for asthma within the region of analysis. The figure shows some very high rates of ED admissions between 8.5 and $25.6 \%$, as indicated by the dark block groups. The average admission rate for children in the region is between 4 and $7 \%$. These rates of ED admissions are not expected to be as high 


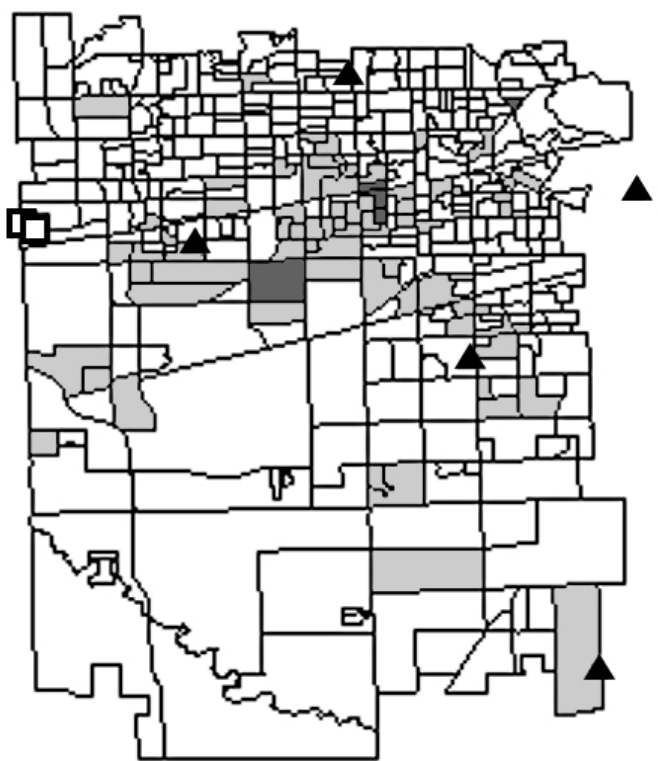

$0-0.31 \square 0.031-0.085$

Figure 2: Rates of ED admissions for asthma. The dark block groups have ED admissions rates between 8.5 and $25.6 \%$. The grey block groups are between 3.1 and $8.5 \%$. The white block groups range from 0 to $3.1 \%$.

as the average asthma rate for the general population in South-western Detroit, because not all asthmatics in a block group will go to the ED for treatment. Therefore, the high rates of ED admissions in some blocks, shown in Figure 2, should be of some concern.

The MC for the map of rates of ED admissions is 0.33 and is highly significant; there is evidence of spatial autocorrelation. The Local Moran Test was utilized to determine if the autocorrelation is localized. The circular areas in Figure 3 indicate the statistically significant regions of localized asthma clustering. These areas are very close to each other and could be thought of as a few small clusters or as one large cluster. The results of the Local Cluster Test are consistent with the location of the observed high rates of ED admissions, as indicated by the dark block groups in Figure 2.

\section{Outdoor air pollution analysis}

The Lawson and Waller's Score Test, which evaluates whether high rates of ED admissions are clustered around the factories, is found to be statistically insignificant with a $p$-value of 0.50 . Given a Monte

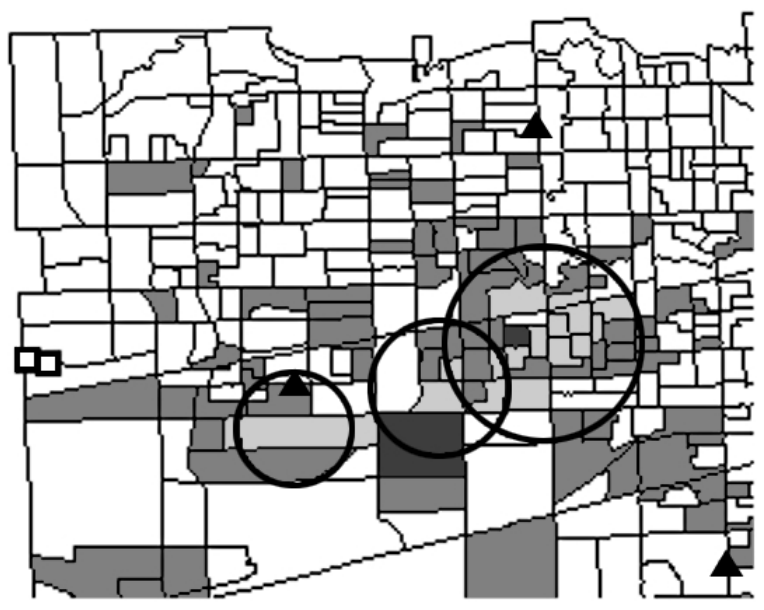

Figure 3: Localized asthma clusters. The Local Moran Test identified 15 block groups which are more similar to their neighbors, than would be expected from a random distribution. These block groups are surrounded by the circles in the figure and each circle represents a cluster of high rates of ED admissions for asthma. Again the squares represent the industrial facilities and the triangles are the hospitals in the study.

Carlo distribution, generated from the rates of ED admissions in this dataset, the asthma values surrounding the two factories are in the centre of the probability distribution. However, since the score test does not consider the possibility that outdoor air pollution rises above the nearest block groups and has its largest impact some distance downwind, Screen3 outdoor air pollution model has also been utilized. First, the Screen3 model is run without any weather data to see the location of the worst case pollution under different weather scenarios. Screen3 predicts the worst outdoor air pollution in the region of the local asthma clusters (1500-5000m East of the source) only under class $\mathrm{E}$ or $\mathrm{F}$ stability conditions (highly stable conditions). If the air is not very stable, then the dispersion occurs more quickly and the worst outdoor air pollution is predicted closer to the source. Class $\mathrm{E}$ and $F$ stability conditions occur very rarely, so that in general, the worst outdoor air pollution from the source does not correlate with the region of local asthma clusters. However, if the wind is blowing in an easterly direction, then there is some outdoor air pollution reaching the local asthma cluster, even if most of the outdoor air pollution may not be impacting the area.

The Screen3 model was run for 18, 19 and 20 September and 13 and 14 November 1993, 1995, and 
1996. These dates were selected because they occur in the autumn, when there are, in general, higher levels of ED admissions. There was not a strong association between outdoor air pollution from these facilities and ED asthma admissions, as can be seen in Table 2. On just five of the 15 days, the wind was blowing in the direction of the asthma cluster, and on just two of those days there is more than one admission, which is the average rate of asthma admission over the five and a half years of the study. Also, on just five of the 15 days, the Screen 3 model prediction correlates with the resulting number of asthma admissions (this is represented by the 'Yes' in column 5, Table 2). Furthermore, incorporating a lag period of 1 or 2 days also results in a general lack of correlation between the Screen3 model prediction and the pattern of ED asthma admissions. Utilizing the winddirection data from 15-30 September 1997, one of the three highest 16-day periods of asthmatic ED visits, also indicates little association between outdoor air pollution from these facilities and asthma admissions, as can be seen in Table $3 . \ln 10$ of the 16 days, the wind was blowing in the direction of the asthma cluster, but only five of those days have more than one asthma admission. On just six of the 15 days, the Screen 3 model prediction correlates with the number of asthma admissions on that day. (This is represented by the 'Yes' in column 5, Table 3). Incorporating a lag period of 1 or 2 days also does not explain the pattern of asthma admissions.

Windrose plots also do not show significant association with air pollution from these two facilities and asthmatics visiting the ED. The windroses for 1990, 1991, and 1992 demonstrate that the primary downwind direction is in the $70-110^{\circ}$ range; the same direction as the local asthma cluster. However, Figure 4 shows the general wind trends for September of 1992, a month in which there usually are high asthma admissions. This plot is similar to the 1991 and 1990 plots and since weather patterns tend to be similar from year to year, the plot is therefore assumed to be similar for the 1993-98 time period. This plot shows that the primary downwind direction is not towards the local asthma cluster. Therefore, the windrose is not suggestive of a relationship between ED admissions for asthma and outdoor air pollution from these factories, since September is a month of high asthma

Table 2: Screen3 results from September and November, 1993, 1995, and 1996

\begin{tabular}{|c|c|c|c|c|}
\hline Date & $\begin{array}{l}\text { Number of asthmatic } \\
\text { ED visits in the } \\
\text { region of analysis }\end{array}$ & $\begin{array}{l}\text { Direction the } \\
\text { wind is blowing } \\
\text { (degrees) }\end{array}$ & $\begin{array}{l}\text { Does Screen3 predict } \\
\text { some air pollutants } \\
\text { in region of analysis? }\end{array}$ & $\begin{array}{l}\text { Does the Screen3 } \\
\text { prediction correlate } \\
\text { with above average } \\
\text { asthmatic ED visits? }\end{array}$ \\
\hline 18 Sept. 1993 & 2 & $260-340$ & No & No \\
\hline 19 Sept. 1993 & 1 & $330-60,100-160$ & Yes & No \\
\hline 20 Sept. 1993 & 1 & $50-90$ & Yes & No \\
\hline 13 Nov. 1993 & 3 & $120-230$ & No & No \\
\hline 14 Nov. 1993 & 4 & $240-320,20-80$ & Yes & Yes \\
\hline 18 Sept. 1995 & 4 & $350-10,150-220$ & No & No \\
\hline 19 Sept. 1995 & 2 & $300-360,70-160$ & Yes & Yes \\
\hline 20 Sept. 1995 & 2 & $0-50$ & No & No \\
\hline 13 Nov. 1995 & 0 & $0-50,160-230$ & No & Yes \\
\hline 14 Nov. 1995 & 2 & $300-350$ & No & No \\
\hline 18 Sept. 1996 & 1 & $320-360$ & No & Yes \\
\hline 18 Sept. 1996 & 2 & $290-360$ & No & No \\
\hline 18 Sept. 1996 & 1 & $130-325$ & No & Yes \\
\hline 13 Nov. 1996 & 1 & $40-90,250-330$ & Yes & No \\
\hline 14 Nov. 1996 & 2 & $130-210,300-350$ & No & No \\
\hline
\end{tabular}

If the wind is blowing in the direction range of 70 and $110^{\circ}$, then Screen3 does predict some air pollutants in the region of analysis and a 'Yes' is in column 4. If the number of asthmatic ED visits is higher than 1, then there is an above average number of visits on that day. If an above average number of asthmatic ED visits correlates with a 'Yes' in column 4, then there is a 'Yes' in column 5. Also, if a below average number of asthmatic ED visits correlates with a 'No' in column 4, then there is a 'Yes' in column 5. 
Table 3: Screen3 results from September, 1997

\begin{tabular}{|c|c|c|c|c|}
\hline Date & $\begin{array}{l}\text { Number of asthmatic } \\
\text { ED visits in the } \\
\text { region of analysis }\end{array}$ & $\begin{array}{l}\text { Direction the wind } \\
\text { is blowing } \\
\text { (degrees) }\end{array}$ & $\begin{array}{l}\text { Does Screen3 predict } \\
\text { some air pollutants } \\
\text { in region of analysis? }\end{array}$ & $\begin{array}{l}\text { Does the Screen3 } \\
\text { prediction correlate } \\
\text { with above average } \\
\text { asthmatic ED visits? }\end{array}$ \\
\hline 15 Sept. 1997 & 3 & $110-190$ & Yes & Yes \\
\hline 16 Sept. 1997 & 0 & $40-150$ & Yes & No \\
\hline 17 Sept. 1997 & 0 & $100-190$ & Yes & No \\
\hline 18 Sept. 1997 & 1 & $100-160$ & Yes & No \\
\hline 19 Sept. 1997 & 4 & $100-160$ & Yes & Yes \\
\hline 20 Sept. 1997 & 2 & $140-210,250-360$ & No & No \\
\hline 21 Sept. 1997 & 2 & $100-270$ & Yes & Yes \\
\hline 22 Sept. 1997 & 3 & $130-160$ & No & No \\
\hline 23 Sept. 1997 & 0 & $150-220,0-70$ & Yes & No \\
\hline 24 Sept. 1997 & 4 & $0-120,300-360$ & Yes & Yes \\
\hline 25 Sept. 1997 & 3 & $120-240$ & No & No \\
\hline 26 Sept. 1997 & 0 & $200-230,0-50$ & No & Yes \\
\hline 27 Sept. 1997 & 1 & $0-100,200$ & Yes & No \\
\hline 28 Sept. 1997 & 2 & $0-110,170-290$ & Yes & Yes \\
\hline 29 Sept. 1997 & 3 & $120-180$ & No & No \\
\hline 30 Sept. 1997 & 5 & $150-220$ & No & No \\
\hline
\end{tabular}

If the wind is blowing in the direction range of 70 and $110^{\circ}$, then Screen3 does predict some air pollutants in the region of analysis and a 'Yes' is in column 4. If the number of asthmatic ED visits is higher than 1, then there is an above average number of visits on that day. If an above average number of asthmatic ED visits correlates with a 'Yes' in column 4, then there is a 'Yes' in column 5. Also, if a below average number of asthmatic ED visits correlates with a 'No' in column 4, then there is a 'Yes' in column 5.

admissions yet the predominant downwind direction is away from the local asthma cluster.

\section{Spatial association analysis}

Figure 6 shows the spatial representation of the proportion of African Americans per block group and median household income per block group, respectively. Comparing Figure 5 with Figure 2 demonstrates that a high proportion of African Americans per block group (dark color in Figure 5) appears to correlate with high rates of ED admissions per block group (dark color in Figure 2), but there are some block groups with high proportions of African Americans which do not have high rates of ED admissions. Similarly, block groups of low median household income (dark color in Figure 6) appear to correlate with high rates of ED admissions and high proportions of African Americans. Although there are a few block groups of low median household income which do not correlate with either high rates of ED admissions or high proportion of African Americans. Maps with Arab Americans and Hispanics and Whites per block group were also analysed but there did not appear to be correlation between those three races and high rates of $E D$ admissions for asthma. Table 4 shows the 10 block groups with highest rates of ED admissions, and how they correlate with proportion of African Americans per block group and median household income per block group. The average percentage of African Americans is $9 \%$ and the average median household income is US\$33 350 in this dataset. Seven of the 10 block groups have a percentage of African Americans greater than $75 \%$. Eight of the 10 block groups have a median household income below the average.

With a stepwise multiple linear regression procedure, the following equation was fitted to the block group data:

Rate of ED admissions for asthma $=0.020+$ $0.046 \times$ proportion of African Americans. 


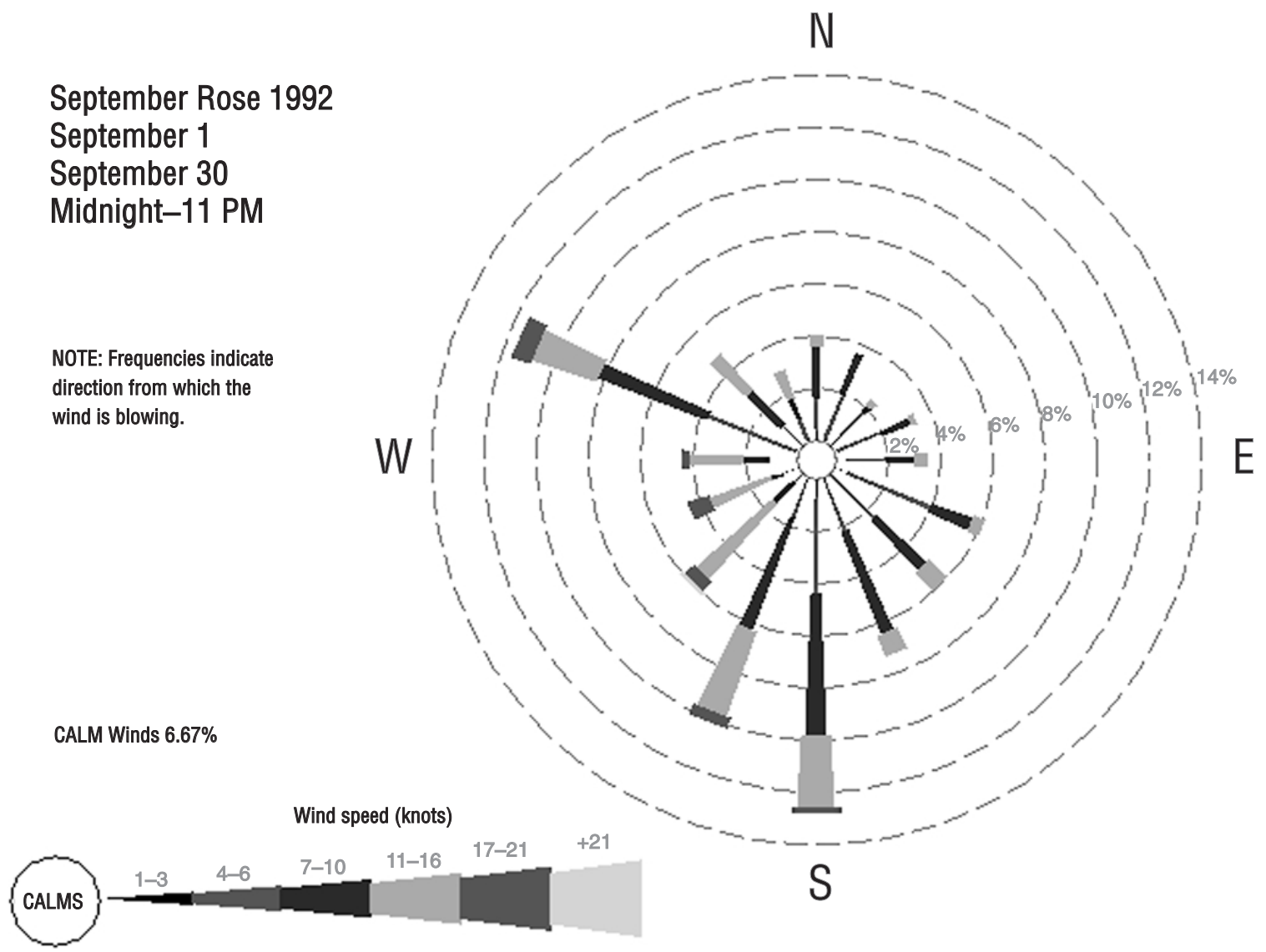

Figure 4: Windrose plot for September 1992. This figure shows that the predominant downwind directions, $-340-20$ degrees, and 110 degrees, do not correlate very well with the location of the local asthma clusters. This is surprising, since the month of September tends to have high numbers of visits to the ED for asthma. This suggests that air pollution from the facilities in this study does not correlate with ED visits by asthmatics.

Table 4: Proportion of African Americans and median household income for 10 bock groups with the highest rates of ED admissions for asthma

\begin{tabular}{lccc}
\hline $\begin{array}{l}\text { Rate of ED admissions } \\
\text { for asthma }\end{array}$ & $\begin{array}{c}\text { Proportion of } \\
\text { African Americans }\end{array}$ & $\begin{array}{c}\text { Children aged 0-15 } \\
\text { in a block group }\end{array}$ & $\begin{array}{c}\text { Median household } \\
\text { income (US\$) }\end{array}$ \\
\hline 0.256 & 0 & 43 & 40500 \\
0.156 & 0.25 & 32 & 16250 \\
0.148 & 1 & 135 & 28750 \\
0.141 & 0.83 & 64 & 24167 \\
0.116 & 1 & 127 & 30132 \\
0.102 & 0.76 & 31 & 30707 \\
0.097 & 0 & 198 & 48750 \\
0.086 & 0.97 & 592 & 16750 \\
0.084 & 0.98 & 756 & 6771 \\
0.074 & 0.96 & 45 & 20114 \\
\hline
\end{tabular}

In general, there is association between high rates of ED admissions for asthma and high proportion of African Americans and low median household income. Also, there appears to be an association between a high proportion of African Americans and low median household income. In the dataset, the average proportion of African Americans is 0.09 and the average median household income is US\$33 350 . 


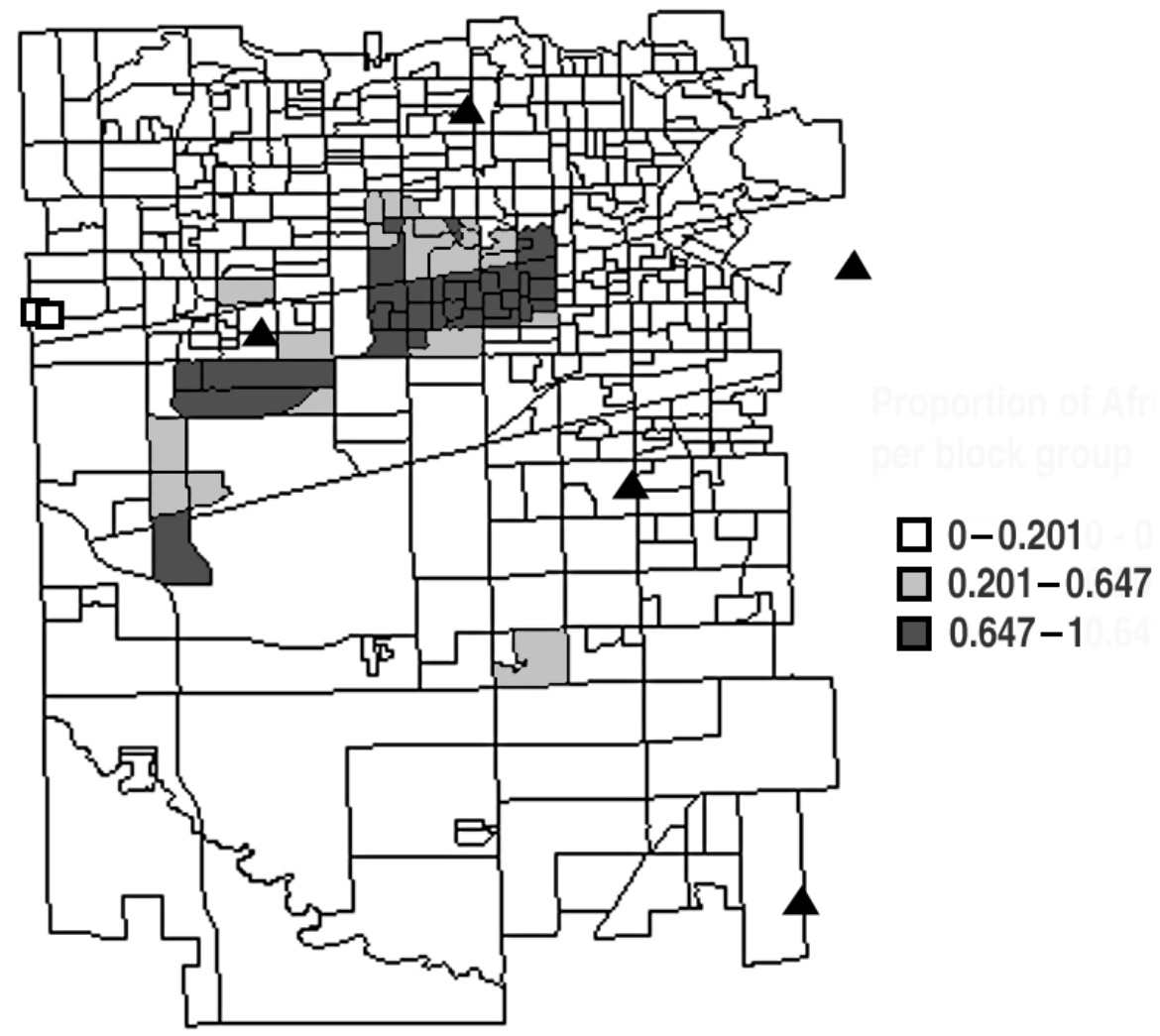

Figure 5: Proportion of African Americans. The block groups of high proportions of African Americans appears to overlap the high asthma rate clusters from Figure 2. The dark block groups show proportions of African Americans of 0.647-1. The grey block groups show proportions of 0.201-0.647. The white block groups show proportions of 0-0.201.

Whites, Hispanics, median household income, and any interaction terms were all insignificant. Median household income and proportion of African Americans are redundant predictor variables in this model. Much of the information, pertaining to rate of ED admissions, which is explained by median household income is also explained by the proportion of African Americans. On its own, median household income is a significant predictor of rate of ED admissions, but is no longer significant if the proportion of African Americans is added to the model. This linear model is highly significant, at the 0.001 level, with an $R^{2}$ of 0.23 . Even when reducing the sample size to 218 , rather than 411 , as a way of accounting for the redundancy in spatially autocorrelated data, the model is still significant at the 0.001 level. Therefore, there is an association between rate of ED admissions and proportion of African Americans; and some of that association could be explained by the redundant predictor variable, median household income. Interesting exceptions to these associations are the two block groups in Table 4 with above average median household income and no African Americans.

\section{Discussion}

An objective of this study was to utilize spatial analysis tools to better understand the relationship between outdoor air pollution from two large automobile coating and assembly factories and ED admissions for asthma. A previous study of asthma in Detroit focused on the elderly and found no significant correlation between asthma and outdoor air pollution. ${ }^{36}$ In this study, block groups with high rates of ED admissions are clustered east of two of the three largest air polluting facilities in Wayne County, Michigan. The Lawson and Waller's Score Test, did not find a cluster of high rates of ED admissions surrounding the facilities. This may be due to the fact that the plume of outdoor air pollution is dispersed above the area 
directly adjacent to the facilities. Screen3 outdoor air pollution model indicates that the worst outdoor air pollution from these facilities is very rarely impacting the asthma cluster. Screen3 also demonstrates that days of high asthma admissions do not correlate with days in which the wind is blowing outdoor air pollution predominately into the region of the asthma cluster, even if a lag period of one or two days is incorporated. Therefore, the tools in this study do not demonstrate a convincing relationship between outdoor air pollution from these facilities and high rates of ED admissions for asthma.

The linear regression model demonstrates a statistically significant correlation between high rates of ED admissions and high proportions of African Americans per block group. An association between low median household income and high rates of ED admissions per block group is also identified, although it is a smaller association which is no longer significant when the proportion of African Americans is added to the model. According to the 1990 census, the study area is comprised of $84 \%$ white, $12 \%$ African American, 2\% Hispanic, and 2\% Arab American. However, Arab American is not a census category, and can only be inferred from the use of an Arab language in the home. Due to misclassification, both the demographics and effects of race on asthma are distorted in the study area. The Detroit area has the largest Arab American population (about 200000 people) in the United States. It is conceivable that Arab Americans of different nationalities have different asthma rates, as has been found in a recent study of different nationalities of the Hispanic population in New York City. ${ }^{37}$ It would be interesting to determine if Arab children are particularly vulnerable to asthma, either because of genetic predisposition, cultural/nutritional differences, or environmental factors.

There are many other risk factors for pediatric asthma which are not included in this study: allergies to pollen, pet dander, dust mite, parental cigarette smoke, genetic susceptibility, and immunity which may be spread through breast feeding. ${ }^{38}$ Because of these other mediating factors, a large correlation between asthma and race and household income may be unrealistic. A study that used GIS to derive asthma clusters based on zip codes in New York City found statistically significant correlation between asthma, percentage of African Americans, and below average household income. ${ }^{23}$ However, the study by Claudio et $a{ }^{23}$ had Pearson correlation coefficients, between asthma hospitalization rates and either median household income or percentage minorities, no smaller than 0.5 , and frequently as large as 0.8 . The study presented in this paper presents a linear regression model with an $R^{2}$ of only 0.23 . One possible reason for the different results between the two studies may be the high prevalence of asthma among Puerto Ricans compared to other racial groups in New York City or different distributions of other risk factors or activity patterns between the two cities. Another possible reason for the differences in results is the spatial unit of analysis used in the two studies. This study demonstrates that there is much variation between different block groups within a zip code, suggesting that the block group level of analysis provides added insights which cannot be perceived at the zip code level. Ideally, a map would consist of individual case locations, but to protect the privacy of the individuals and to incorporate population differences between areas, the cases have been aggregated to the smallest possible census-defined geographical boundary, a block group.

One limitation of the study is the possibility that the polygon-shaped region of analysis (Figure 1), is populated by children who attend an ED of a hospital that is not in this study. The five hospitals in this study represent $60-70 \%$ of the total ED visits in Western Wayne County and there is little difference in the capabilities of different hospitals to treat asthmatics. ${ }^{30}$ Based on this information, we have made the assumption that most asthmatics will attend the closest ED, and therefore we believe the polygon-shaped region of analysis to be well represented by children who attend an ED of a hospital in this study.

Some of the most serious limitations in this study are the quality of the surrogates used to represent asthma, outdoor air pollution, race, and class. Individuals who use the ED to treat asthma may not have a similar geographical distribution to all other asthma sufferers. Some children may have better access to their primary physicians and therefore go to that physician when they have an asthma episode. A study in Los Angeles shows that low family income is a predictor of hospital admissions for asthma. ${ }^{39}$ Therefore, because this study uses ED data, one might expect to see a correlation between asthma and low household income. This correlation does not necessarily indicate a higher prevalence of asthma in poorer 
areas, but may just indicate that wealthier children have better access to preventive care and/or better access to their primary physician when experiencing an asthma episode, or else manage their disease better. Therefore, ED visits may be an indication of a poorly managed disease and lack of patient education, rather than an indication of asthma exacerbations. ${ }^{40,41}$ Therefore, the use of the ED to treat asthma could be viewed as an indication of asthma severity, and may not reflect asthma prevalence in a region.

Another limitation is the lack of spatially representative outdoor air pollution data. In an ideal situation, an exposure grid of different air pollutants could be placed on top of Figure 2 to determine if rates of ED admissions correlate with outdoor air pollution. There are no monitoring stations in the study region and the intermingling of outdoor air pollution models with GIS is still in its infancy. Furthermore, Screen 3 model is a basic screening model which only models pollutants from one source, whereas a multi-source model would be more appropriate in any air pollution study. It is important to note that the two facilities in this study primarily emit Volatile Organic Compounds (VOCs), and significantly smaller amounts of the classes of chemicals (PM, NOx, $\mathrm{SO}_{2}$, and ozone) which are more frequently associated with asthma admissions. Perhaps a study of the Rouge Steel facility, located just outside the study area, which leads the county in $\mathrm{PM}, \mathrm{NOx}$, and $\mathrm{SO}_{2}$ pollution, would have indicated a positive association with ED admissions. Unfortunately, two of the larger hospitals surrounding this facility would not provide us with their ED asthma data. Therefore, the possibility that the ED admissions are associated with emissions from Rouge Steel facility could not be evaluated. Nearly all associations between asthma and race or household income are based on neighborhood block group characteristics, and not individual patients, which can lead to the risk of the ecological fallacy (making individual-level inferences from group-level data). However, the database does include some racial information and the correlation between asthma and African Americans at the block group level is similar to the correlation that exists at the individual level. One last limitation is the weakness of a linear regression model to detect an association between race and SES and asthma admissions. A more sensitive and specific analysis would involve a logistic regression model which could calculate relative risks of different risk factors and ED admissions for asthma.

\section{Implications for practice}

This study demonstrates the use of GIS technology and spatial analysis tools to evaluate spatial environmental epidemiological hypotheses. This study illustrates the need for population-based, as opposed to hospital-based, asthma data to aid in the evaluation and analysis of asthma-related risk factors. This study also illustrates the need for block-groups, as opposed to zip codes, to enhance the sensitivity of spatial epidemiological analyses. The results of this study indicate that hospitals and health departments should focus on low income families when conducting interventions to minimize ED admissions for asthma. The tools in this study do not demonstrate a convincing relationship between outdoor air pollution from these two industries and rates of ED admissions for asthma, but outdoor air pollution from other facilities in the region cannot be ruled out.

\section{Acknowledgements}

The authors thank Robin Chirillo, and Sharon Zalays of Oakwood Health System, and Gary Ley of Garden City Hospital for providing access to the emergency room data. The authors also thank Bob Miljan of the Wayne County Department of Health, Health Emergency Medical Services Department, for information concerning the catchment areas of different emergency services in Wayne County. The assistance of Ann Chevelier and Peter Warner of the Wayne County Air Quality Laboratory is recognized for providing wind data for Wayne County. The authors also thank Andy Long, Mark Wilson, Geoff Jacquez, Leah Estberg, Dan Griffith, and Sandra Arlinghaus for their thoughtful questions and insights and their help with the spatial presentation and spatial analysis.

\section{References}

1 Mannino D M, Homa D M, Pertowski C A, Ashizawa A, Nixon L L, Johnson C A, Ball L B et al. (1998) Surveillance for asthma. United States 1960-95 Morbidity and Mortality Weekly Report CDC Surveillance, 47: 1-27.

2 Burt C W, Knapp D E. (1996) Ambulatory Care Visits for Asthma (1993-94): United States Advance Data No. 277. National Center for Health Statistics.

3 Schappert S M (1997) Ambulatory care visits to physician offices, hospital outpatient departments, and 
emergency departments. United States 1995 National Center for Health Statistics, Vital Health Statistics, 13: 129.

4 Weiss K B, Gergen P J and Hodgson T A (1992) An economic evaluation of asthma in the United States. New England Journal of Medicine, 326: 862-866.

5 United States Department of Health and Human Services (1996) Healthy People 2010 Objectives: Draft for Public Comment. Advance Data No. 278. National Center for Health Statistics, Hyattsville, MD.

6 Sears M R (1997) Epidemiology of childhood asthma. The Lancet, 350: 1015-1020.

7 Von Mutius E, Martinez F D, Fritzsch C, Nicolai T, Roell $\mathrm{G}$ and Theimann H-H (1994) Prevalence of asthma and atopy in two areas of West and East Germany. American Journal of Respiratory and Critical Care Medicine, 149: 358-364.

8 Magnussen H, Jorres R and Nowak D (1993) Effects of air pollution on the prevalence of asthma and allergy: lessons from German reunification. Thorax, 48: 879.

9 Arden Pope III C (1989) Respiratory disease associated with community air pollution and a steel mill, Utah Valley. American Journal of Public Health, 79: 623628.

10 Arden Pope III C (1991) Respiratory hospital admissions associated with PM10 pollution in Utah, Salt Lake, and Cache Valleys. Archives of Environmental Health, 46: 90-97.

11 Low R B, Sinert R and Bielory L (1996) Atmosphere and asthma in New York City 1989-95. Academic Emergency Medicine, 3: 457.

12 Ponka A (1991) Asthma and low level air pollution in Helsinki. Archives of Environmental Health, 46: 262.

13 Dockery D W, Speizer F E, Stram D O, Ware J H, Spengler J D and Ferris B G, Jr (1999) Effects of inhalable particles on respiratory health of children. American Review of Respiratory Disease, 139: 587-594.

14 Koenig J Q, Covert D S, Marshall S G, Belle G V and Pierson W E (1987) The effects of ozone and nitrogen dioxide on pulmonary function in healthy and in asthmatic adolescents. American Review of Respiratory Disease, 136: 1152.

15 Evans R (1992) Asthma among minority children: a growing problem. Chest, 101 (6): 368s-371s.

16 Kelso T M, Self $T H$, Rumbak M J, Stephens M A, Garrett W and Arheart K L (1995) Educational and longterm therapeutic intervention in the ED: effect on outcomes in adult indigent minority asthmatics. American Journal of Emergency Medicine, 13: 632-637.
17 McDermott M, Silva J, Rydman R, Giacheloo A L, Yarzagaray E, Robinson D, Peragallo $\mathrm{N}$, Barquero $\mathrm{H}$ and Arrom J O (1996) Practice variations in treating urban minority asthmatics in Chicago. Journal of Medical Systems, 20: 255-266.

18 Hartert T V, Windom Hh, Peebels R S, Freidhoff L R and Togias A (1996) Inadequate outpatient medical therapy for patients with asthma admitted to two hospitals. American Journal of Medicine, 336: 1356-1363.

19 Jacquez G M (1998) GIS as an enabling technology. In: Gatrell A C and Loytonen M, eds. GIS and Health. Taylor \& Francis, London, pp. 17-28.

20 Kulldorff M and Feuer E J (1997) Breast cancer clusters in Northeastern United States: a geographical analysis. American Journal of Epidemiology, 146: 161-170.

21 Rushton $G$ and Lolonis P (1996) Exploratory spatial analysis of birth defects in an urban population. Statistics in Medicine, 15: 717-726.

22 Jacquez J M and Kheifits L I (1993) Synthetic cancer variables and the construction and testing of synthetic risk factor maps. Statistics in Medicine, 12: 1931-1942.

23 Claudio L, Tulton L, Doucette J and Landrigan P J (1999) Socioeconomic factors and asthma hospitalization rates in New York City. Journal of Asthma, 36: 343-350.

24 Dunn C E, Woodhouse J, Bhopal R S and Acquilla S D (1995) England: addressing public concern by combining geographical and epidemiological methods. Journal of Epidemiology and Community Health, 49: 395-400.

25 Chan-Yeung M and Malo J L (1994) Aetiological agents in occupational asthma. European Respiratory Journal, 7: 346-371.

26 US Environmental Protection Agency. (1994) Health Effects Notebook for Hazardous Air Pollutants. Review Draft, December. Environmental Protection Agency, Washington DC.

27 National Institute for Occupational Safety and Health. (1996) Registry of Toxic Effects of Chemical Substances. National Institutes of Health, Rockville, MD.

28 Jacquez G M, Grimson R, Waller L A and Wartenberg D (1996) The analysis of diease clusters, part II: introduction to techniques. Infection Control and Hospital Epidemiology, 17: 385-397.

29 Anselin L (1995) Local indicators of spatial associationLISA. Geographical Analysis, 27: 93-115.

30 Waller LA, Turnbull B W, Clark L C and Nasca P (1992) Chronic disease surveillance and testing of clustering of disease and exposure: application to leukemia incidence and TCE-contaminated dumpsites in upstate New York. Envirometrics, 3: 281-300. 
31 Griffith D and Lagona F (1998) On the quality of likelihood-based estimators in spatial autoregressive models when the data dependence structure is misspecified. Journal of Statistical Planning and Inference, 69: 153-174.

32 Dutilleul P (1993) Modifying the $t$-test for assessing the correlation between two spatial processes. Biometrics, 49: 305-314.

33 Richardson S (1990) A method for testing the significance of geographical correlations with application to industrial lung cancer in France. Statistics in Medicine, 9: 515-528.

34 Rossi O V J, Kinnula V L, Tienari J and Huhti E (1993) Association of severe asthma attacks with weather, pollen, and air pollutant. Thorax, 48: 244.

35 Greenberg L, Field F, Reed J I and Erhardt C L (1964) Asthma and temperature change. Archives of Environmental Health, 8: 642.

36 Schwartz J (1994) Air pollution and hospital admissions for the elderly in Detroit, Michigan. American Journal of Respiratory and Critical Care Medicine, 150: 648-655.

37 Ledogar R J, Penchaszadeh A, Garden C C I and Acosta L G (2000) Asthma and Latino cultures. different prevalence reported among groups sharing the same environment. American Journal of Public Health, 90: 929-935.

38 Clark N M, Brown R W, Parker E, Robins T G, Remick D G, Jr Philbert M A, Keeler G J et al. (1999) Childhood asthma. Environmental Health Perspectives, 107 (Suppl. 3): 421-429.

39 Nauenberg E and Basu K (1999) Effect of insurance coverage on the relationship between asthma hospitalizations and exposure to air pollution. Public Health Reports, 114: $135-148$.

40 Kesten S, Szalai J and Dzyngel B (1995) Air quality and the frequency of emergency room visits for asthma. Annals of Allergy, Asthma and Immunology, 74: 269.
41 Bielory $L$ and Deener A (1998) Seasonal variation in the effects of major indoor and outdoor environmental variables on asthma. Journal of Asthma, 35: 7-48.

\section{Biosketches}

Jerome O. Nriagu is Professor and Director of the Environmental Health Sciences Program.

Jaymie R. Meliker is a doctoral student in the Environmental Health Sciences Program.

Adnan S. Hammad is Director of the Community Health Center at ACCESS.

Kathryn L. Savoie is Director of the Environmental Program at ACCESS.

Jeffrey M. Devries is Director of Children's Health Services at Oakwood Healthcare System, located in the Detroit Metropolitan Area.

Financial disclosure: There are no organizations with a direct financial interest in this manuscript.

Correspondence: Jaymie Meliker, University of Michigan, School of Public Health, Department of Environmental Health Sciences, 109 S. Observatory St., Ann Arbor, MI 48109-2029, USA

Tel: +1 734615 2596; Fax: +1 734764 9424; e-mail: jmeliker@umich.edu 